\title{
Study on influential parameters of hybrid AFM processes: a review
}

\author{
Chinu Kumari and Sanjay Kumar Chak* \\ Division of Manufacturing Processes and Automation Engineering, Netaji Subhas Institute of Technology, \\ New Delhi 110078, India
}

Received: 17 July 2019 / Accepted: 20 September 2019

\begin{abstract}
The abrasive flow machining (AFM) processes are ultra-precise finishing techniques widely used as finishing solutions for micro/nano finishing of inaccessible contours on difficult to machine components. The AFM processes use highly visco-elastic properties of the abrasive laden medium as a cutting tool for deburring, edge rounding and polishing the surface. Due to the design of workpiece holder and hybridization of basic AFM, the complex shear modulus of the abrasive laden medium can locally be influenced and thus a targeted removal of material from workpiece can be achieved, as a result, there was improved performance, productivity, surface integrity, and texture. This article addresses the detailed classification of AFM processes based on the use of different energy and tooling and highlights the critical outcomes in each category. The objective of this article is to review and summarize various process parameters of AFM processes like extrusion pressure, medium flow volume, medium flow rate, number of cycle, viscosity, workpiece geometry, etc. and their effects on roughness value and material removal rate. Key capabilities and noted findings concerning various AFM processes in addition to their applications and future challenges are also discussed in this paper.
\end{abstract}

Keywords: Abrasive flow machining / magnetorheological finishing / hybrid abrasive flow machining / abrasive medium

\section{Introduction}

In the modern era, deterministic high precision finishing methods are of great importance and are the requirement of present manufacturing scenario due to their most critical, labor-intensive and highly uncontrollable nature. Conventional finishing processes like grinding [1], super-finishing [2], honing [3] are good only for finishing the flat and cylindrical surfaces. The finishing of a complicated turbine blade made of super-alloy and holes and slots in glass and semiconductor was difficult if conventional processes were used [4-7]. Also, when the roughness value required in micrometer/nanometer range, the cost of machining increases sharply [8-12]. To overcome these problems of conventional machining processes, researchers have developed advanced finishing processes. Majority of the advanced finishing processes uses loose flowing irregularly shaped abrasives that act as a flexible cutting tool [13-15]. Abrasive flow machining (AFM) is one of the abrasive based advanced finishing processes [16] and one of the best processes for micro/nano-finishing the complex contours.

\footnotetext{
* e-mail: sanjaykchak@yahoo.com
}

This process includes a semi-solid abrasive laden medium was extruded under pressure through or across the surface to be machined [17-19]. The medium acts as a flexible tool having unique deformable ability whenever it subjected to any restriction. This unique deformable ability of medium was responsible for its movement through any shape of the passage [20-25]. AFM machines were classified according to the flow of medium in three different ways; one way AFM [26], two way AFM [27] and orbital AFM [28]. Commonly used AFM process was two-way AFM in which abrasive medium was pushed to and fro through the passages formed by the workpiece $[29,30]$. The major problems associated with AFM process were low productivity rate, uncontrolled forces that affect the final surface finish and therefore, restrict its usage only to finish the internal surfaces. To overcome these problems and have better abrasion with high finishing rate, AFM process has been hybridized with some other conventional/nonconventional machining processes [31-35]. Various hybrid AFM processes; CFAAFM, R-AFF, DBG-AFF, MAAFM, ECAFM, and UAAFM had been developed by various researchers. These hybrid processes can be classified in two different ways; one in which all constituent processes were directly involved in the material removal and surface finish which permits unrestricted use, distribution, and reproduction in any medium, provided the original work is properly cited. 
and other in which the processes assist in removal/finishing by changing the condition of machining in a positive direction. The CFAAFM, R-AFF, DBG-AFF were center tooling-based AFM processes having different arrangement inside the workpiece to create relative motion between workpiece and medium. The magnetic field was used around magnetorheological fluid in the MAAFM process for more control on finishing force. The conventional ECM and ultrasonic machining assist the advanced AFM process for giving double cutting action. Through these hybrid AFM processes, 50-80\% improvement in surface roughness value was observed as compared to basic AFM. These hybrid processes can be used to finish prismatic workpieces of various shapes; internally as well as externally. Significant elements of the AFM for controlling process technology were machine, tooling and abrasive medium [36-39]. Multiple investigations carried out by the researchers to identify the effects of process parameters like extrusion pressure, the number of cycles, viscosity, abrasive concentration and grain size on the output responses; surface finish and material removal during the experiment [40-44]. The AFM processes with their experimental values of parameters are explained in Table 1. It was found that extrusion pressure with processing time was the most dominating process parameter that affects the responses.

AFM is a fluid-based finishing process; most of its parameters are related to the abrasive laden medium. Various types of fluids used by the researchers have also been discussed in this review paper. Finally, an attempt has been made to highlight the key capabilities of various AFM processes with cost efficiency analysis in addition to future trends.

\section{Developments in AFM process}

The AFM process provides better results for machined components that require the removal of imperfection created by mechanical processes. This makes AFM ideal for the radiusing, surface stress relief, polishing, geometry optimization and deburring [16]. The AFM is the need of present industries, so there is large research work reported in this field. In this section, there is a brief summarization of development in the field of AFM from initial to today.

Extrude Hone Corporation USA, established AFM in 1960. AFM can be thought as a process of generating selfdeforming tool that precisely removes workpiece material and finishes the surface at those areas restricted to medium [29]. The mechanism of material removal comprises three different deformation modes; one is elastic deformation correlated with rubbing, second is plastic deformation or ploughing, where the majority of the material is displaced without being removed and the last one is micro-cutting [45-49]. Initially, Rhoades et al. [26] developed one way AFM process in which the medium travels in one direction and concluded it was the simplest \& least time-consuming process [50-56]. It was found that surface roughness can be reduced from 75 to $90 \%$ on the cast, machined or EDM surfaces with dimensional tolerances up to $\pm 0.005 \mathrm{~mm}$. For better radiusing and getting finishing action on both inner as well as outer surfaces of a component, Rhoades et al. [27] developed a two-way AFM finishing process. The basic operation of the two-way AFM process consists of two vertical/horizontal opposite hydraulic cylinders and in between the workpiece was clamped by suitable fixtures $[37,57-59]$ as depicted in Figure 1. The pistons in both the cylinders were used to move the abrasive laden medium to and fro over the surface to be finished. In this way, the finishing operation was carried out in two-way AFM process.

In another development, Rhoades et al. [28] used oscillatory motions to the workpiece. As the oscillations continue, the workpiece strikes the abrasive medium with eccentric path causing the complex shape to interact completely with the abrasive medium and results in equal abrasion on all faces. Adsul et al. [60] developed a set-up of AFM on the lathe for carrying an experiment on aluminum and brass. He observed that the dominant factors are abrasive concentration in medium followed by mesh size, the number of cycles and medium flow speed. Improvement in surface roughness was more in case of softer material. Fang et al. [61] considered work efficiency as the most concerned target in AFM. Temperature was the most influencing parameter on work efficiency. Medium temperature increases with increasing cycles, which means medium viscosity decreases with an increase in number of cycles. AFM tests show that increasing cycles extensively decrease material removal rate and surface roughness, hence reduction in efficiency $[12,56]$.

Thus, to enhance the performance and control over rheological properties, researchers have developed the variants of abrasive flow machining process [62-65] by joining the basic AFM process with conventional/unconventional machining processes. The AFM processes are classified according to the forces and energy used in the process [36]. Classification of AFM processes is depicted in Figure 2.

\subsection{Centre tooling based AFM}

In center tooling-based AFM process, a special tool was placed inside the workpiece to increase the finishing rate and aid in intermixing of the self-deforming abrasive laden medium. Sankar et al. [66,67] developed a process termed as drill bit guided abrasive flow finishing (DBG-AFF) by placing drill bit inside the medium flow path as shown in Figure 3 for mixing and reshuffling the abrasives to increase the contact line of abrasives with the workpiece. Walia et al. [68] used centrifugal force-generating (CFG) rod at the center of a workpiece as shown in Figure 4 for creating the centrifugal force on medium to strike the abrasive in a circular motion at hollow cylindrical workpiece that decreases the finishing time and the process was termed as CFAAFM.

In DBG-AFF and CFAAFM, a helical motion was provided only at the center of medium and their very low probability of rotating the medium at the workpieceabrasive region [35]. To overcome this problem, Sankar et al. [69] investigated the process R-AFF in which the workpiece rotates while the reciprocating motion was given 


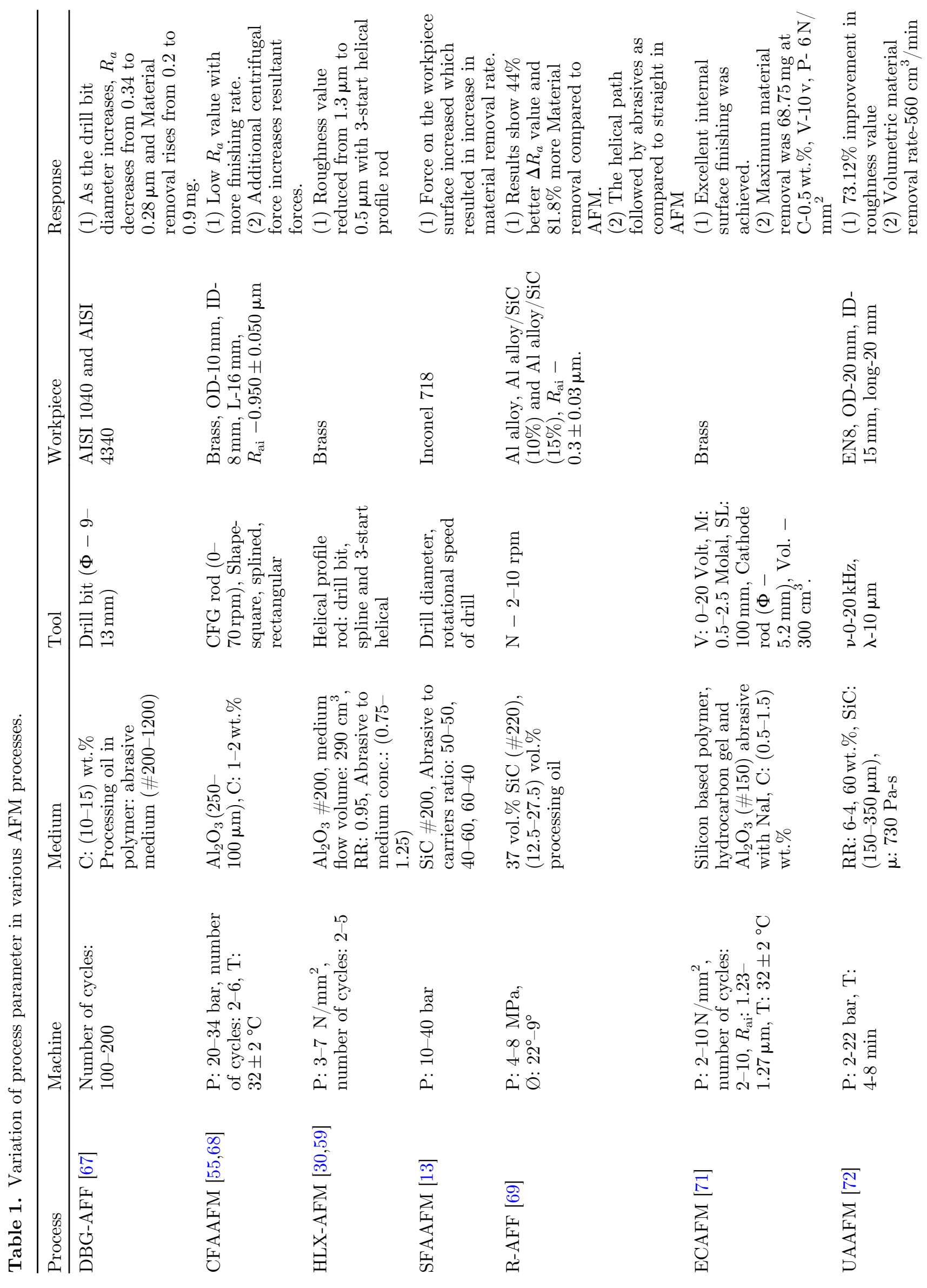




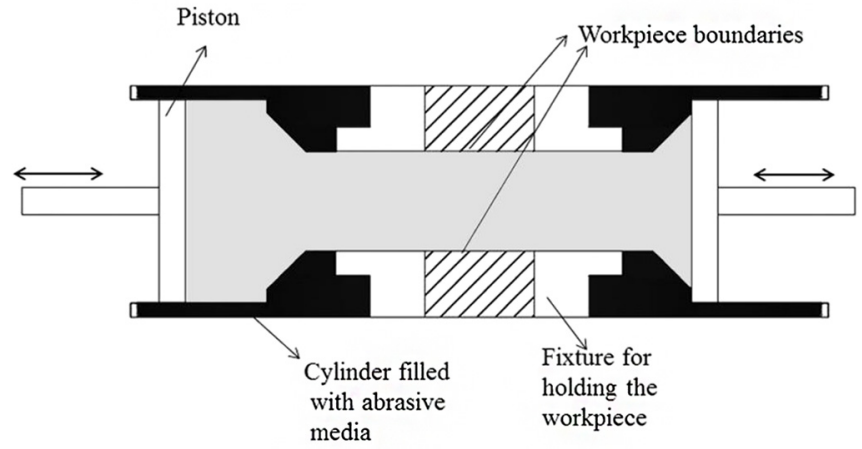

Fig. 1. Schematic of a two-way AFM set-up [37].

to medium for finishing MMC that was difficult to finish by other existing finishing processes. The rotation of workpiece makes abrasives to follow the helical path and shear the peaks at an angle when contact with abrasives. An experimental study was conducted to compare the performances of AFF and R-AFF in terms of $\Delta R_{a}$ and MR. R-AFF produced about $44 \%$ better results in terms of $\Delta R_{a}$ and about $82 \%$ in MR as compared to AFF process [51]. The surface obtained after finishing from R-AFF process were micro cross hatch pattern that could improve the lubricant holding capabilities [52]. To provide helical path to the medium along the axis, Brar et al. [59] used a helical profile rod inside the workpiece. The process was termed as helical abrasive flow machining process (HLX-AFM). Due to the helical profile rod a centrifugal force was acting on the medium in addition to three different medium flow (flute, axial flow, scooping flow and remixing of the medium at the exit from the finishing zone). In this way, the finsihing force was increased on the workpiece which enhanced the material removal by 2.5 times as compared to basic AFM process.

\subsection{Chemical and ultrasonic based AFM}

Imperfections such as out-of-roundness form errors and taper can be corrected by hybridization of AFM with other conventional processes. In this section, hybridization of AFM with chemical and ultrasonic machining is studied on the basis of the literature survey. Dabrowski et al. [70] developed a process named ECAFM their anodic dissolution of work-piece occurs along with multi-cutting by abrasives through back and forth extrusion of the medium. In ECAFM process a low viscous electrolyte-abrasives laden medium can be extruded at low extrusion pressure hence; there was not any requirement of cooling down the medium and suitable for thin and delicate workpieces. Brar et al. [71] studied the effect of process parameters through ECAFM process using response surface methodology. They observed that the ECAFM process have better MRR as compared to AFM. Ranjan et al. [57] developed a chemo-mechanical magnetorheological finishing (CMMRF) process, by combining essential aspects of chemo-mechanical polishing (CMP) process and magnetorheological finishing (MRF) process for silicon and copper alloy. The MR fluid applies polishing pressure on the work surface during CMMRF process. This polishing pressure depends on properties of MR fluid, working gap and 


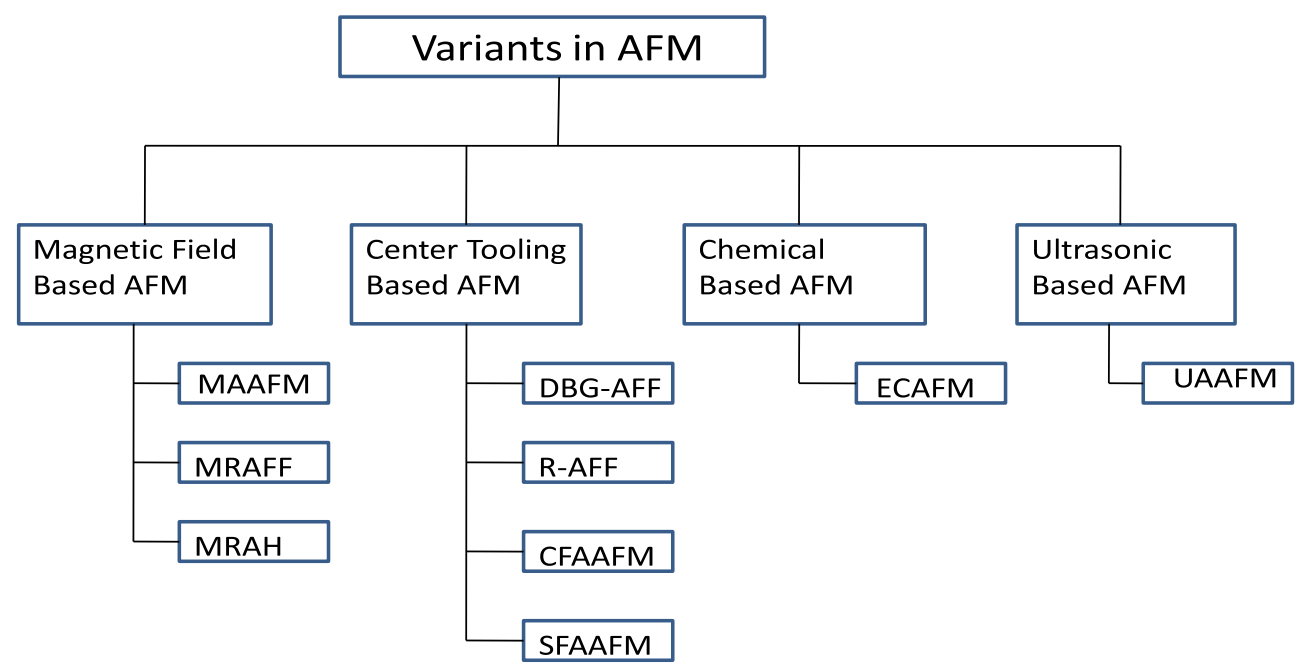

Fig. 2. Variants in AFM.

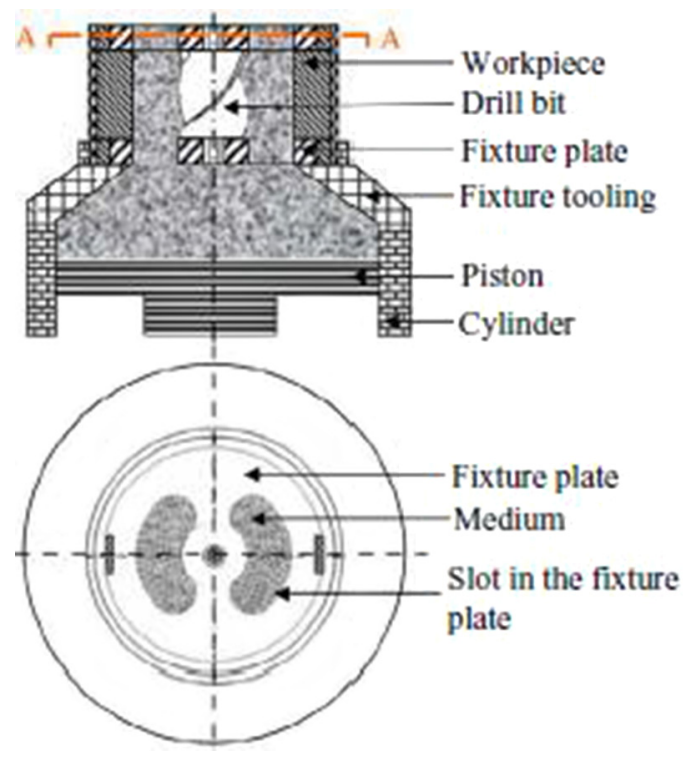

Fig. 3. Schematic diagram of DBG-AFF [67].

rotational speed. Angstrom level of surface finishing can be achieved through CMMRF.

Finishing of the complex external surface was not possible with DBG-AFF, SFAAFM and CFAAFM processes. To finish the external surfaces, Jones et al. [38] developed ultrasonic flow polishing (UFP) by integrating the AFM process with Ultrasonic machining (USM). In which moving abrasives were interacting with the vibrating workpiece at an angle to increase the finishing rate. Venkatesh et al. [72] also developed a new technique called Ultrasonic assisted AFM (UAAFM) in which controlled vibrations were provided to the workpiece at the perpendicular direction to the medium flow to finish very intricate geometries. Through this UAAFM process, about $81 \%$ improvement in surface roughness and $0.05 \%$ improvement in material removal was achieved as compared to basic AFM. Mulik et al. [39] also developed Ultrasonic assisted magnetic abrasive finishing (UAMAF)

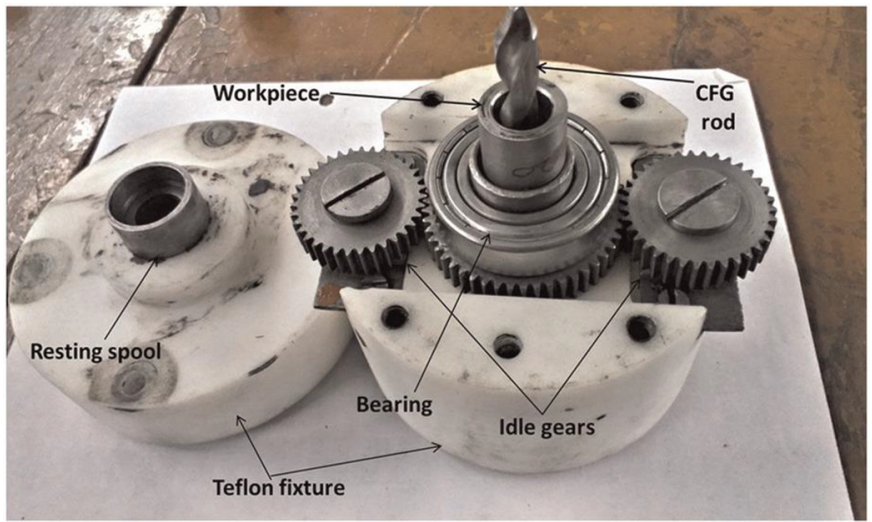

Fig. 4. Elements of the rotating attachment used in the CFAAFM set-up [68].

process by combining two non-traditional processes USM and MAF. $22 \mathrm{~nm}$ surface finish was achieved in $80 \mathrm{~s}$ with hardened steel workpiece. A theoretical model for material removal was also presented by Mishra et al. [32]. He concluded that there was exponential relation between material removal rate and finishing time. Approximately $45 \mathrm{mg}$ weight of SS workpiece was removed in 120 seconds.

\subsection{Magnetic field based AFM}

Singh et al. [73] developed a process named Magnetically assisted abrasive flow machining (MAAFM) for further enhancement in MRR and improve roughness value by polymer base abrasive laden medium mixed with ferromagnetic abrasive particles in AFM process. The magnetic field was applied around the workpiece for finishing complex internal geometry as shown in Figure 5. It was reported that the application of magnetic field enhanced the number of dynamic abrasive involved in cutting. The MAAFM process provides better control over rheological properties of magnetorheological finishing medium as compared to AFM. To add the magnetorheological effect in AFM process the researcher, Jha et al. [47] developed a 


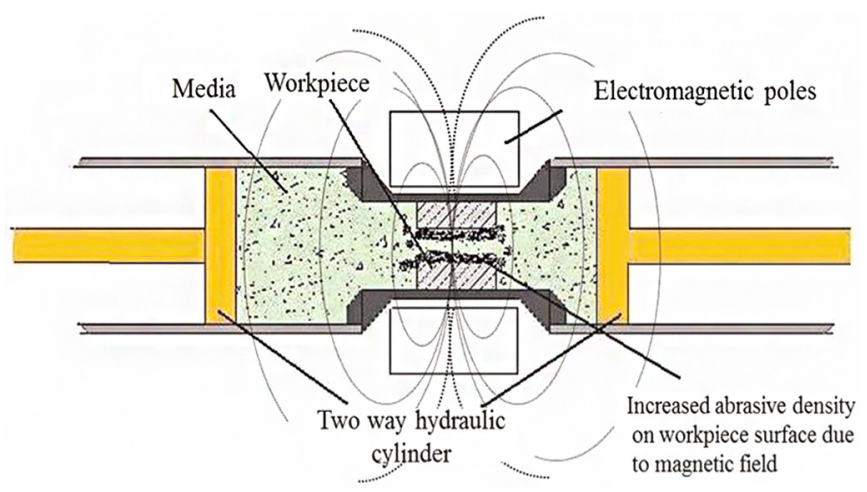

Fig. 5. Schematic diagram of MAAFM set-up [73].

process called Magneto-Rheological Abrasive Flow Finishing (MRAFF) for more precise finishing the workpiece. In this process, the flow of MR fluid occurs over the workpiece surface in the presence of a magnetic field. At zero magnetic field, there was no change in surface roughness; improvement in roughness value was observed only when the magnetic field was increased. In the presence of the magnetic field, the CIPs chains keep on holding abrasives more firmly and thereby result in an increase in the cutting force on abrasive and thus more finishing action. Even the low value of magnetic field 0.15 tesla shows a noticeable difference in roughness value. In another process, Magnetorheological Abrasive Honing (MRAH) [22], the magnetorheological effect was added in the conventional honing process where workpiece rotates while the reciprocating motion was provided to the MR fluid. It was observed that the better finishing was achieved with rougher surface and at a high rotational speed. These magnetorheological processes are mostly used for nano-finishing of complicated surface and external finishing of optical lenses. Sidpara et al. [9] developed a flexible magnetic brush for finishing the freeform titanium knee joint. $28 \mathrm{~nm}$ finishing was achieved in $64.7 \mathrm{~h}$. The problem faced by researcher during finishing was non-uniformity in surface roughness value at all faces and low finishing rate. To overcome these problems, Kumar et al. [19] finished the freeform SS knee joint by R-MRAFF process. In this process, both rotational and reciprocating motion was provided to MR fluid. Surface roughness ranging from 35 to $78 \mathrm{~nm}$ was achieved in $24.7 \mathrm{~h}$ at various locations.

\section{Process parameters of AFM and their effect on responses}

To provide excellent control over these AFM processes, the selection of process parameters is essential. In this paper, AFM process parameters are broadly classified into three categories as shown in Figure 6; the machine, the medium and the workpiece [74,75]. The machine decides the extent of abrasion through process variable of extrusion pressure, flow volume, flow rate and number of cycles [76]. Rheological properties of the abrasive-laden polymeric medium are considered to know the amount of abrasion. The medium grit size, temperature, viscosity and polymer to dilute are the parameters for understanding the rheological properties of MR fluid. Next is workpiece to be finished by AFM process. The properties of the workpiece like initial roughness value, material type, and geometry decides the machining time, type of abrasives used [77]. The process parameters and the responses of various AFM processes are summarized in Table 1.

\subsection{Medium flow volume and extrusion pressure}

Medium flow volume and extrusion pressure are the most influential parameters controlling the amount of abrasion. Greater the volume of medium greater would be the abrasion [77]. Medium flow volume was determined by a term known as 'Slug Length of Flow' by the researchers for calculating the amount of abrasion [78]. It was formulated by dividing the medium flow volume by the cross-sectional area of restricted flow passage [79]. The two passage of different cross-sectional area will give the same flow volume by a larger slug length passage through the smaller cross-sectional area. This restricted area creates more abrasion relative to larger area flow passage. Extrusion pressure strongly affects the final forces acting on abrasive grains. In R-AFF process, as the extrusion pressure increases, $F_{a}$ (axial force) and $F_{r}$ (radial force) also increases, so the shearing of peaks increases up to a certain level $(6.25 \mathrm{MPa})$ beyond it $\Delta R_{a}$ starts decreasing because abrasive grain starts making indentations along with shearing of surface peaks is shown in Figure 7a [69]. The material removal increases continuously with an increase in extrusion pressure but with a decreasing rate as shown in Figure 7b. It was due to the reduction in height of the peaks in the successive machining cycles. When a rotational motion was provided to the workpiece along with a reciprocating motion to abrasive grains, less finishing force was required as compared to basic AFM. In CFAAFM process if we increase the pressure more than the 54 bar, there was rolling of abrasives over the surface without shearing the peaks [68]. Jha et al. [48] studied the effect of extrusion pressure on change in the roughness of stainless steel in MRAFF process. It was observed that $3.75 \mathrm{MPa}$, shows maximum improvement in surface finish due to the optimum combination of the magnetic field induced yield stresses and applied fluid flow shear stresses.

\subsection{Number of cycles and process time}

When number of cycles was increased both material removal and $\Delta R_{a}$ was increased nonlinearly, but after a few cycles, the rate of material removal was decreased with an increase in number of cycles. The reason behind it was that sharper peaks have been finished during the initial cycles only and the flatten surface left after finishing [80]. The required number of cycles for machining these hybrids AFM process were lesser as compared to AFM process [81]. Initially, Ra was decreased with increases in the number of cycles. But after a value of 20 cycles for aluminum (Al) and brass, the tool marks and light abrasive marks become visible and it decreases the Ra. Similar was the case with R-AFF process for $\mathrm{Al}$ alloy/SiC MMCs. As the number of cycles 


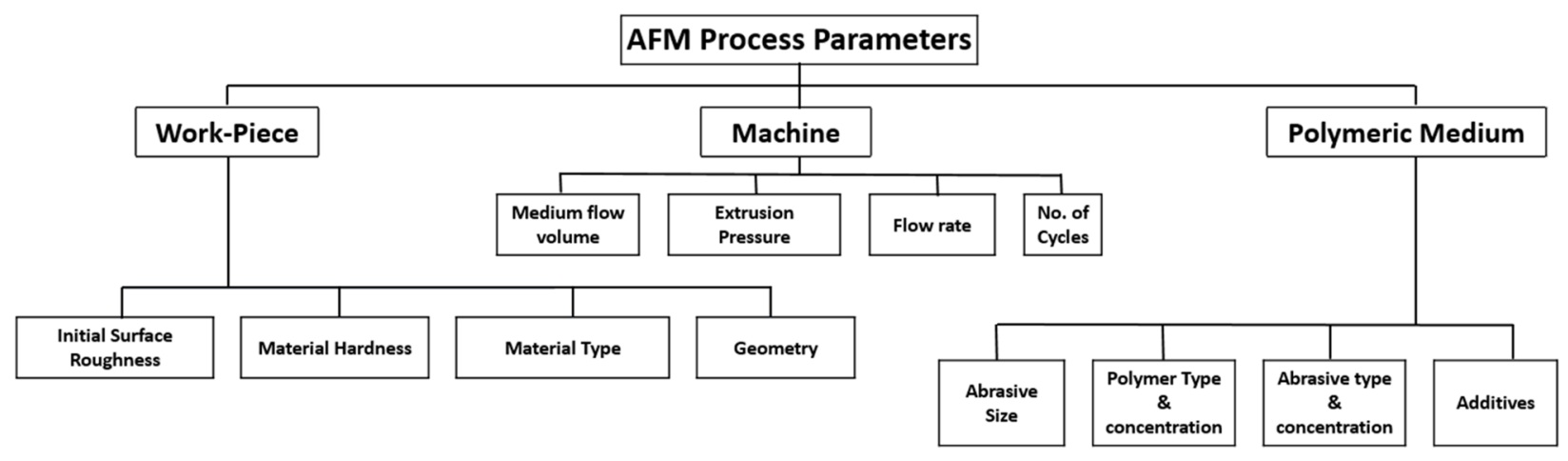

Fig. 6. AFM process parameters.

a

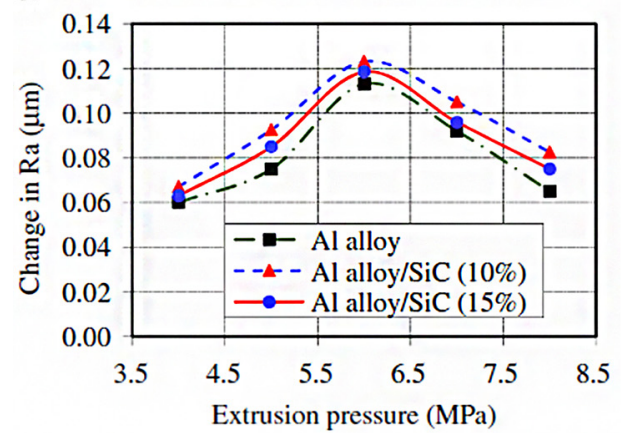

b

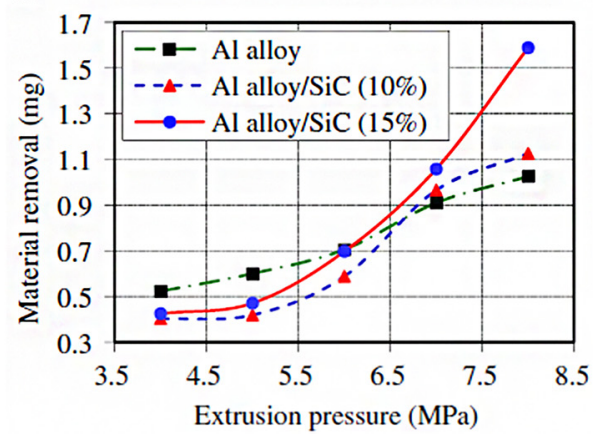

Fig. 7. Variation in (a) $\Delta R_{a}$ and (b) Material removal with plasticizer vol.\% in R-AFF process [69].

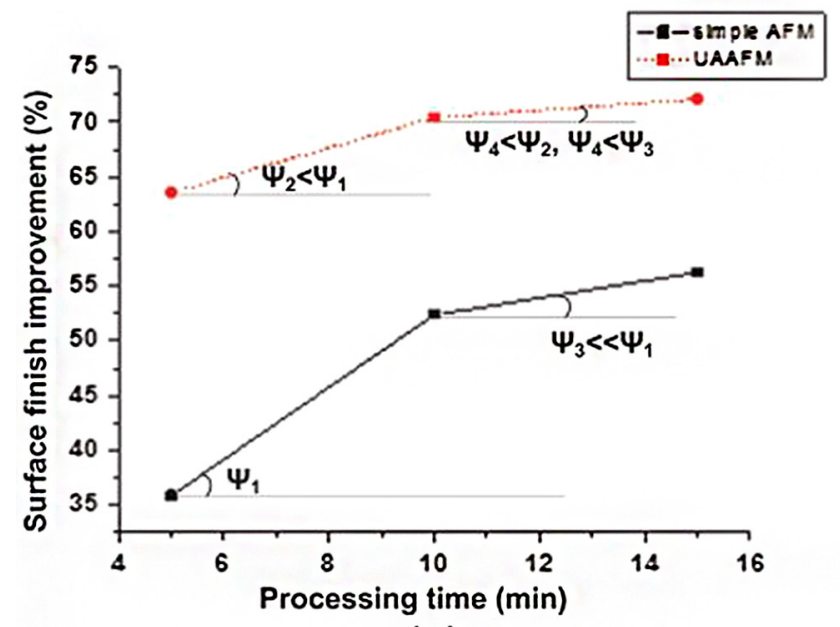

(a)

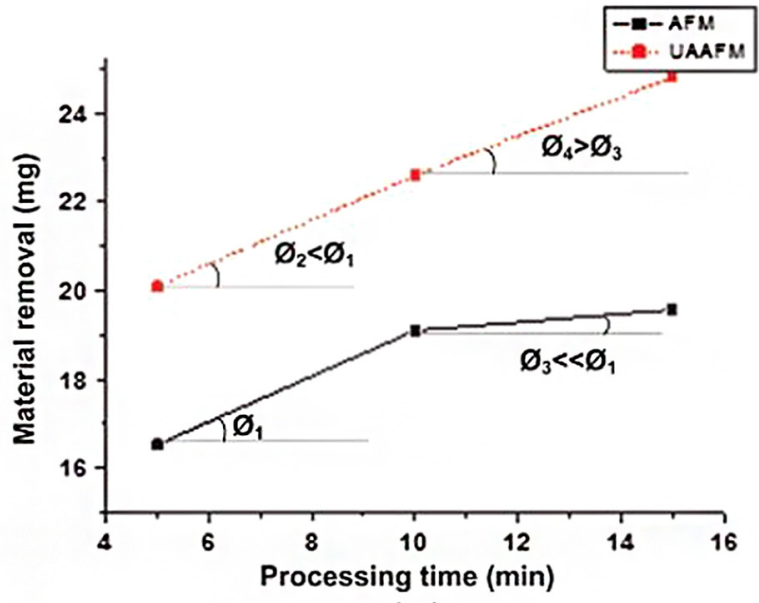

(b)

Fig. 8. Effect of processing time on (a) improvement on the surface finish; (b) material removal [72].

increases, a number of times the abrasives come in contact with the workpiece increases, but after a maximum value of 550 cycles, the reverse will appear [69]. Due to ductile nature of $\mathrm{Al}$, the indentations in $\mathrm{Al}$ alloy and reinforcement pullouts in $\mathrm{Al}$ alloy/SiC MMCs appears after a maximum value because the abrasives try to abrade on the same surface again and again. $\Delta R_{a}$ increased with an increase in processing time in UAAFM process [25], but the surface finish improvement became saturated beyond $10 \mathrm{~min}$ of machining owing to the onset of glazing on the machined surface and slope angle gradually decreases $\left(\Psi_{4}<\Psi_{2}\right)$ as shown in Figure 8a. It was also observed that the UAAFM had better results in terms of material removal as compared to the basic AFM process as shown in Figure 8b. Material removal decreases $\left(\varnothing_{3}<\varnothing_{1}\right)$ with increase in processing time after 10 min due to the reduced effectiveness of the dull abrasives. 


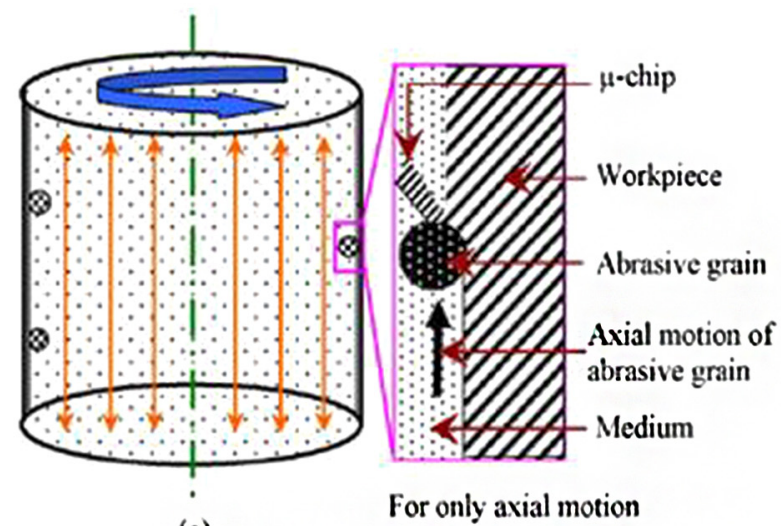

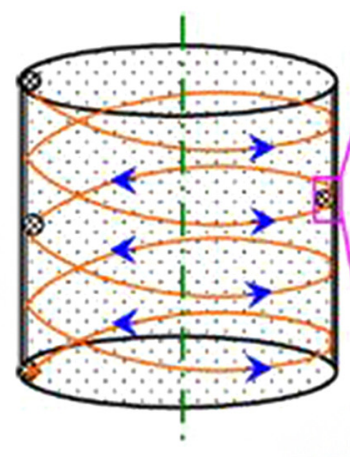

(b)

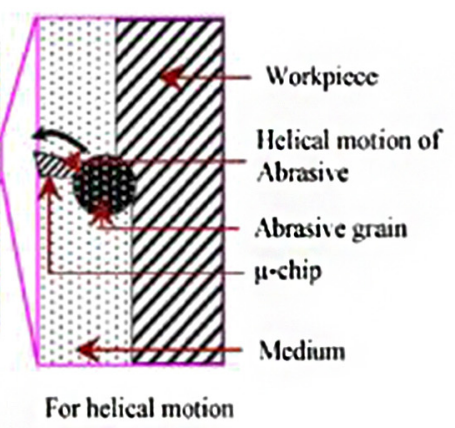

For helical motion

(a)

Fig. 9. Abrasive laden medium motions (a) medium reciprocation and workpiece rotary motion; (b) approximately helical finishing path on the workpiece surface because of simultaneous axial and rotary motion [71].

In the initial phase (before 200 cycles) of finishing of SS workpiece in MRAFF process, decrease in roughness was observed due to ploughing effect and their "Illusive polishing" action which hides the actual surface topography. Owing to appearance of deep grinding marks on the workpiece surface after 200 cycles, surface roughness was increased. As the number of cycles increased beyond 300 , there was a continuous decrease in roughness value till 1000 cycles. A total change in roughness from $0.48 \mu \mathrm{m}$ to $0.32 \mu \mathrm{m}$ was observed [48].

\subsection{Viscosity of the medium}

The viscosity of the medium is one of the most influencing parameters for AFM process. When the viscosity was increased by taking other parameters constant, improvement in material removal and final surface roughness value $[82,83]$ observed. Medium viscosity was affected by parameters like abrasive concentration, grain size, wt.\% of processing oil and their temperature [61]. The temperature was going to increase whenever number of cycles was increased [84]. It was observed that the medium viscosity decreases with an increase in shear rate, wall shear stress, medium-temperature and mesh size. Further, the material removal rate and surface finish decreased with a decrease in the viscosity of the medium [12]. The results of CFAFM show that use of finer grain size of the abrasive particles results in more significant improvement of surface roughness [68]. In HLX-AFM process, higher abrasive concentration in abrasive laden medium leads to more material removal because more abrasive cutting edges are available and also the viscosity of the material was increased [59]. But in the MRF process when the conc. of abrasives was increased, MR chain becomes weak due to the increase in the distance between two CIP, hence change in roughness value and material removal was decreased $[8,10]$. The wt.\% of processing oil in R-AFF should be kept optimum for proper mixing and bonding of abrasives and processing oil. At low processing oil content, the medium does not form a continuous uniform homogenous mass and it was bit stiff which possess poor rheological properties. For Al alloy/MMC optimum value was at around $10 \%$ processing oil [72]. Further increase in processing oil reduces the holding capability of abrasives. After that, the abrasive tries to rotate about its position instead of abrading the surface. William et al. [19,21] used the full experimental plan to study the effect of the extrusion pressure and viscosity on roughness value and material removal in basic AFM process. It was observed that the effect of the viscosity of the medium was more significant on material removal as compared to extrusion pressure.

\subsection{Special parameters of hybrid AFM}

In most of the conventional AFM machines, a workpiece was held in position between the two vertically opposed medium extrusion cylinders [35]. Therefore, there is a limitation to finish a complex surface with sharp edges. To overcome these problems, variants of AFM were developed with a superimposed effect. In CFAFM [68] the medium flow through the workpiece passage and the rotational speed of the rod produces a centrifugal force on abrasive particles in the direction normal to the axial force [28]. The shape of the CFG rod was the most influential parameter in CFAFM process. Different shapes are used for resulting maximum material removal and $\% \Delta R_{a}$. Four types of rod shapes are used in the whole process; square, rectangular, triangular and spline. The rectangular shape CFG rod has maximum $\% \Delta R_{a}$ because it has an optimum angle of impingement of the abrasives on the work surface and has the maximum striking velocity of the abrasive particle [59]. The material removal was maximum for spline shape rod because of its maximum throw ability. In R-AFF [51], rotational motion was provided to the workpiece while the reciprocating motion to the medium (as shown in Fig. 9a) and combine to give a helical motion of abrasives on the workpiece surface as shown in Figure 9b. Due to this, the contact length of the abrasive grains with the workpiece was increased and it shears the surface peaks approximately in the helical path. When the rotational speed of the workpiece was increased, more number of surface peaks encounters the active abrasive grains. Hence, more amount of material was removed. But, beyond the optimum value of 
Table 2. Types of medium used in hybrid processes.

\begin{tabular}{|c|c|c|c|c|}
\hline Process & Polymer carrier & $\begin{array}{l}\text { Abrasives } \\
\text { used }\end{array}$ & Workpiece material & Prominent results \\
\hline Basic AFM [89] & $\begin{array}{l}\text { (a) Natural Rubber (NR) } \\
\text { (b) Butyl Rubber }\end{array}$ & $\mathrm{SiC}$ & $\mathrm{Al}$ and $\operatorname{En} 8$ & $\begin{array}{l}\text { Butyl Rubber based medium } \\
\text { shows good performance as } \\
\text { compared to natural rubber. }\end{array}$ \\
\hline ECAFM [71] & $\begin{array}{l}\text { Polypropylene glycol and } \\
\text { polyethylene glycol }\end{array}$ & $\mathrm{Al}_{2} \mathrm{O}_{3}$ & $\begin{array}{l}\text { Electrically conductive } \\
\text { material }\end{array}$ & $\begin{array}{l}\text { (1) Excellent internal surface } \\
\text { finishing. } \\
\text { (2) Electrolyte abrasives laden } \\
\text { medium can be extruded at low } \\
\text { extrusion pressure. }\end{array}$ \\
\hline MAAFM [73] & $\begin{array}{l}\text { (1) Silicon-based polymer } \\
\text { (2) Ferromagnetic } \\
\text { constituents }\end{array}$ & $\mathrm{Al}_{2} \mathrm{O}_{3}$ & Brass & $\begin{array}{l}\text { Increase in the strength of the } \\
\text { medium by applying magnetic } \\
\text { field. }\end{array}$ \\
\hline R-AFF [90] & $\begin{array}{l}\text { Styrene-Butadiene Rubber } \\
\text { (SBR) }\end{array}$ & $\mathrm{SiC}$ & $\begin{array}{l}\text { (Al alloy, } \mathrm{Al} \text { alloy } / \mathrm{SiC} \\
\text { with } 10 \% \mathrm{SiC} \text { and } \\
15 \% \mathrm{SiC}) \mathrm{MMC}\end{array}$ & $\begin{array}{l}\text { Rheological properties of medium } \\
\text { were modified for getting good } \\
\text { results regarding material } \\
\text { removal rate and surface finish. }\end{array}$ \\
\hline MRAFF [47] & Paraffin oil and grease & Sic & SS & $\begin{array}{l}\text { Better surface finish as compare } \\
\text { to AFM }\end{array}$ \\
\hline
\end{tabular}

$8 \mathrm{rpm}$ [69], $\Delta R_{a}$ starts slightly decreasing because the velocity at which the abrasive strikes the surface peak was so high, it might start creating deeper scratches which leading to lower $\Delta R_{a}$. For frequent reshuffling of abrasive particles, the drill bit was inserted inside the medium [67]. Due to the combination of three different flows; flow along the flute path, reciprocating axial flow and scooping flow, the workpiece-abrasive contact length was curved hence, the number of peaks that to be sheared was increased, leading to higher material removal. When the drill bit diameter was increased, the cross-sectional area for the flow of medium was decreased and ultimately the resistance for the flow was increased and has high $\Delta R_{a}$. However, after a certain limit, it was deteriorated due to the heavy pressure of abrasive grains. In HLX-AFM process, $15 \%$ better surface finish was achieved with 3-start profile as compared with standard helical drill-bit with no increase in the operating pressure [59]. In all magnetically assisted process when the magnetic field was increased, more abrasive wear takes place with an overall enhancement of material removal rate and surface roughness value [80]. In UAAFM [71], if ultrasonic frequency increases from 0 to $15 \mathrm{kHz}$, the relative velocity of abrasives hitting the target surface has been increased, but at a higher frequency, of about $15-20 \mathrm{kHz}$ deeper scratches were observed leading to falling in $\Delta R_{a}$. The most significant factor in UAAFM was the applied frequency that helps in attaining an improvement in surface finish up to $80.12 \%$ at $7 \mathrm{kgf} / \mathrm{cm}^{2}$ extrusion pressure. The maximum value of material removal obtained in UAAFM was $14.5 \mathrm{mg}$. Nagdeve et al. [15] fabricated the fixture of the knee joint for defining the machining and to direct the MR fluid to the areas where surface improvements were desired. The surface roughness up to $28 \mathrm{~nm}$ and area roughness up to $6.64 \mathrm{~nm}$ was achieved.

\subsection{Flow rate of the medium}

Medium flow rate is the least influential parameter of the AFM process. For the AFM process, there was slightly increment in material removal\& surface roughness value was noticed on increases the medium flow speed. There was an adverse effect of increased flow rate on both material removal and final roughness value in MAAFM [73]. Experimental results show that the effect of the magnetic field appears less on high flow rate. At high medium flow speed, the particles are not attracted to the workpiece surface for a longer period, resulting in less concentration on the workpiece wall. Further, the fast-moving medium takes the abrasive out of the influence of the magnetic field before they strike the workpiece surface. In MRAH process, the reciprocating motion provided to the MR fluid did not provided an aid for finishing. However, it was only for reshuffling the medium.

\subsection{Selection of medium}

At the heart of AFM process, the abrasive laden medium is used that acts as a self-deforming grinding tool and a key element of the AFM process. The medium consists of two components; carriers (viscoelastic materials) and solid phase (abrasives and particles to assist the abrasive). The three basic characteristics of high-quality AFM medium are better flow-ability, self-deformability and abrading ability to finish the given surface to nano-scale. Many efforts were made by the researchers to improve the properties of the AFM medium. Various AFM medium used by the researchers are mentioned in Table 2 .

The most widely used AFM medium are Silicon-based medium, Polypropylene glycol, Natural polymer-based medium and Rubber-based medium [85-88]. Jain et al. [60] used the mixture of silly putty (silicon-based), abrasive 
particles (silicon carbide), and varnish oil for finishing the $\mathrm{Al}$ and brass workpiece by AFM process. It was observed that the concentration of abrasives was the most dominating parameter followed by number of cycles, mesh size and flow rate. The use of the medium depends on the type of process and material used. Kar et al. [89] developed an alternate medium of butyl rubber for AFM process. The long branched chemical structure of butyl rubber as compared to natural rubber support high shear stress value. A mixture of styrene-butadiene rubber-based medium was used in R-AFF [90] for finishing the MMC of $\mathrm{Al}$. The results of styrene-butadiene rubber were better than natural rubber medium and butyl rubber in terms of improvement in surface roughness value. The ECAFM [71] process has used polymeric electrolyte (polypropylene glycol and polyethylene glycol) to carry the abrasive particles for electrically conductive material. This medium improves the rate of finishing as compare to basic AFM. The temperature rise of the abrasive laden medium is the main problem associated with AFM process. At high temperature, the viscosity of AFM medium decreases ultimately the stress carrying capacity reduces [61]. Sharma et al. [87] developed a polymer abrasive based medium for finishing brass workpiece which can withstand high temperature up to $71^{\circ} \mathrm{C}$. In magnetic assisted AFM processes, the ferromagnetic particles were used with abrasives whereas in MRAFF processes magnetorheological (MR) fluid was used. The MR fluid for nano-finishing in MRAFF process can finish almost every material from hard titanium to soft copper alloy [49,50]. Sankar et al. [91] observed that AFM has better material removal rate for freeform knee joint made up of stainless steel (time taken: $15 \mathrm{~h}$ ) as compared to other advanced abrasive based finishing processes like magnetorheological fluid based finishing (MRFF) for titanium knee joint (time taken: $64.7 \mathrm{~h}$ ) and R-MRAFF for stainless steel knee joint (time taken: $24.83 \mathrm{~h}$ ). In the MRFF process, the force acting on the individual abrasive particle was low and in R-MRAFF process, the medium was viscoplastic and viscosity was quite low as compared to viscoelastic AFM medium. The surface roughness value obtained through AFM process in the range of $42.9-62.5 \mathrm{~nm}$.

\subsection{Material and geometrical configuration of workpiece}

In the past, the AFM process was used only for hard and brittle materials. Today, this process can be used to machine many types of materials from brittle to ductile and hard to soft. Researchers worked on various materials like $\mathrm{Al}$, Al alloy/MMC, brass, Cu, EN8, mild steel, stainless steel, etc. In the case of MAAFM [73] process, three different types of materials (brass, $\mathrm{Al}$ and mild steel) were used with different value of hardness and ductility. The material removal and $\Delta R_{a}$ were more for the brass workpiece, but for Al these values are less. Due to high ductility of the Al, the pits created by abrasives would be filled by the metal in the vicinity by the subsequently following abrasive particles in the flowing medium. Consequently, more material was required to remove from
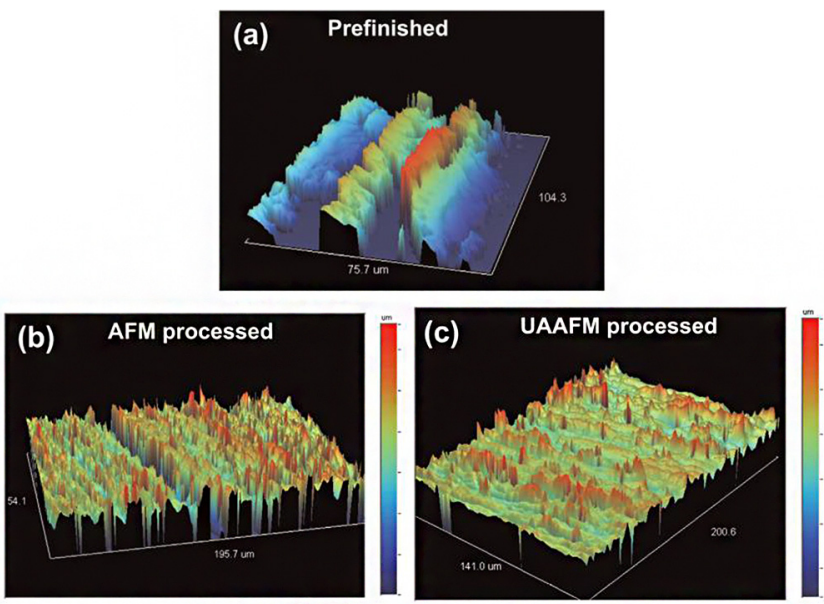

Fig. 10. Topography of the machined surfaces obtained through optical profilometer: (a) prefinished, (b) AFM processed and (c) UAAFM processed [72].

the surface and there was not any significant improvement in surface roughness value. For mild steel, the material removal and change in roughness value are less because of its high hardness, and due to its magnetic property there was a shielding effect. The R-AFF process [52] can machine MMC up to micro/nano level in less processing time as compared to other conventional machining processes. MMC (metal matrix composites) material showed better results with $10 \% \mathrm{SiC}$ as compared to $15 \% \mathrm{SiC}$. The probability of reinforcement agglomeration was more in $\mathrm{Al}$ alloy/SiC (15\%) compared to $\mathrm{Al}$ alloy/SiC (10\%). The bonding strength at the interface of reinforcements was lower as compared to matrix reinforcement bonding strength. During machining, the reinforcement pullout occurs which leaves the deep cavity. The process termed as UAAFM [49], was used to finish bevel gear made up of EN8. This was the external complex surface, which was finished by UAAFM. Figure 10 shows the surface topographies of the workpiece surface before finishing and, after finishing through conventional AFM and UAAFM processed surfaces. There was significant improvement in surface roughness through UAAFM. Ghadikolaei et al. [92] studied the three materials; stainless steel, $\mathrm{Al}$ and $\mathrm{Cu}$ in terms of surface finish under different operating condition of magnetic field strength, abrasive particle size and finishing time. Experimental results of MRAFF shows that in all operating conditions, $\mathrm{Cu}$ showed better results due to its ductile nature, more purity and better magnetic properties as compared to Al. Effect of magnetic field was investigated on two different workpieces; magnetic and non-magnetic under MRAH process. The roughness value of magnetic materials (mild steel) was changed from $0.173 \mu \mathrm{m}$ to $0.16 \mu \mathrm{m}$ in the absence of magnetic field and when magnetic field was present the workpiece gets magnetized and movement of abrasives were restricted around the workpiece. The noticeable change in roughness for nonmagnetic workpiece (stainless steel) from $0.15 \mu \mathrm{m}$ to $0.11 \mu \mathrm{m}$ was observed in $20 \mathrm{~min}$. It was also observed that the process was suitable for finishing the non-magnetic material as compared to magnetic materials. Kumar et al. 
Table 3. Key capabilities and noted findings of AFM processes.

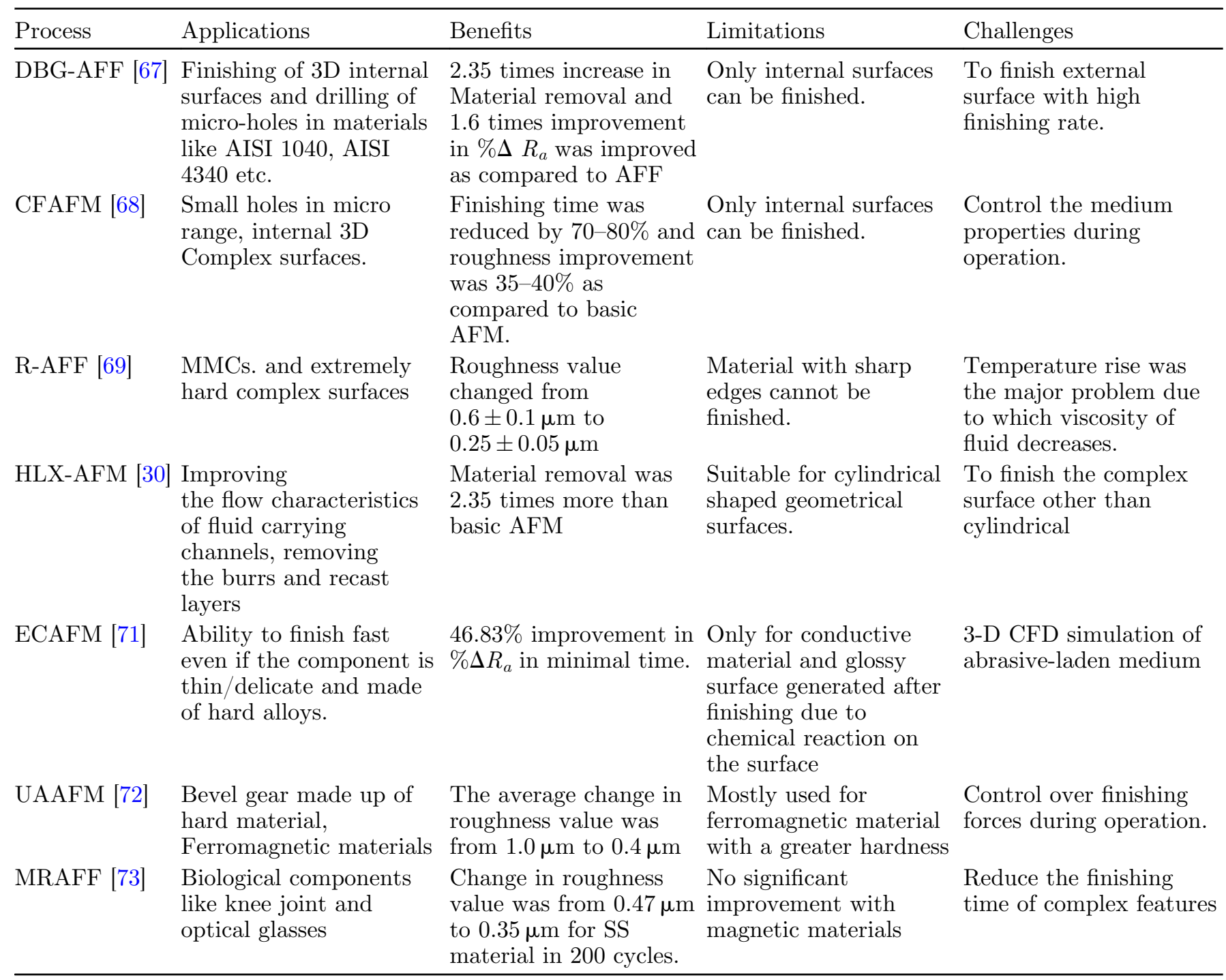

[32] takes three ductile materials (gunmetal, brass and mild steel) as workpiece. These materials were finished by HLX-AFM. It was observed that the brass has more material removal as compared to other materials due to its softer nature.

\subsection{Cost analysis of various AFM processes}

The finishing operation carries about $15 \%$ of the total cost. Cost increases sharply if the surface roughness value of less than $1 \mu \mathrm{m}$ was required [22]. AFM is a cost-effective finishing process for finishing the extrusion dies, aeroplane, medical and electronics components. It is a fully automatic process by which multiple parts can be finished simultaneously. Automatic AFM system is capable of handling thousands of parts per day. Hence, labor cost and tedious work reduce significantly [65]. In AFM process, loose abrasives are used as a cutting tool, so there is no tool aging and tool changing problem. At high flow rate and high temperature, there is less risk of machine and tool failure. It provides economic, consistent and predictable results by understanding and controlling the process parameters that can be applied to a range of applications. To increase the capability of AFM regarding effectiveness and production rate, AFM process can be hybridized with other processes. The results of various hybridized AFM processes are very encouraging and are the demand of the future.

\section{Applications of AFM}

Precision finishing of mechanical parts is a critical requirement in many applications. There are some traditional as well as non-traditional processes available; however, most of the processes are unable to finish the complex geometries. AFM is one of the non-traditional finishing processes that have the potential to overcome this problem. Through AFM processes nano-level surface finish had been achieved, deburr holes of size as small as $0.2 \mathrm{~mm}$ 


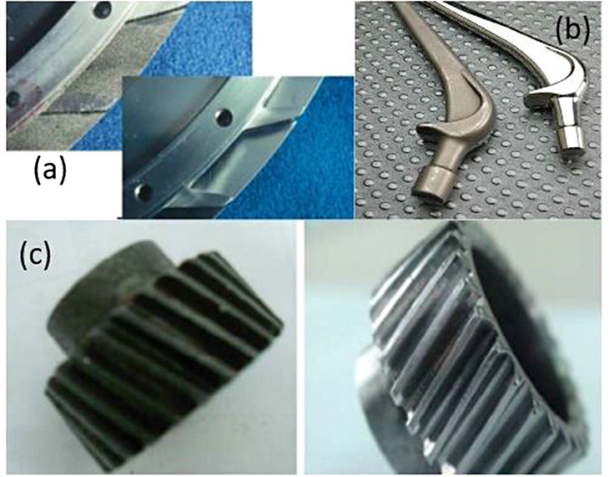

Fig. 11. Surface finish improvement before and after on (a) internal passages within turbine engine diffuser [94], (b) medical implants [93], (c) complex helical gear [72].

and radius edges from $0.025 \mathrm{~mm}$ to $1.5 \mathrm{~mm}$ [38]. AFM processes have a wide range of applications in almost every field where precise finishing is required such as aerospace, electronics, medical, automobile and in manufacturing industries for making dies and moulds [93-100]. In the aerospace industry, AFM plays a significant role as it was used to remove the carbon deposits from the engine. The exhaust manifold of an automobile contains several runners that have a complex geometry $[32,46]$. To achieve the desired airflow rate in the manifold, AFM has proved to be a better solution [42]. Hybridization of AFM process increases the capability of AFM process as explained in Table 3. UAAFM [72] technique was used to finish bevel gears up to maximum level. Bevel gears are used in many diverse applications such as differential drives in an automobile, rotorcraft drive system, locomotives, marine applications, railway track, etc. The human implants components require nanoscale surface roughness as per ASTM requirements $[13,40]$. For medical industries, AFM process is capable of finishing knee joint to the nanometer scale by applying the magnetic field around the medium $[7,30]$. Apart from the above-mentioned applications, AFM can be used to finish a variety of materials of different shapes. Figure 11 shows some engineering and medical parts finished by various AFM processes.

\section{Conclusions}

AFM is a well-established advanced finishing process capable of meeting the desired finishing requirements. It is commonly used to finish complex shapes for better surface finish values and tight tolerance. However, the major disadvantages of this process have difficulty in machining the materials like Inconel 718, MMC's. Low surface finish \& surface integrity with high machining time is also a major problem associated with AFM. To overcome these problems many modifications as explained above (CFAAFM, DBG-AFF, R-AFF, ECAFM, MAAFM, etc.) have been tried with AFM process. These hybrid AFM processes increase the effectiveness of the process regarding surface roughness and material removal rate. For better control of these hybrid processes, there is a need to optimize the process parameters like extrusion pressure, flow rate, the viscosity of medium, etc. In CFAAFM and SFAAFM, special tooling to rotate the medium was used. Best results regarding $\Delta R_{a}$ and material removal was obtained with rectangular shape CFG rod. Coupling of the chemical action of ECM with abrasion action of AFM in ECAFM makes the process more effective and overcome the low productivity limitation of AFM. Better surface finish for non-ferrous materials like brass and less number of cycles for the same material removal rate was reported with MAAFM as compared to primary AFM process. However, it was also stated that there was only a marginal improvement in surface finish took place with mild steel. This process was inappropriate for ferrous materials. For finishing the external surface and where the rotation of workpiece and medium was not possible, researchers recommended the use of UFAFM. There was a substantial improvement in the roughness value of EN8 bevel gear.

However, some challenges still exist in AFM processes. Some of the future recommendations are suggested below.

- The AFM processes have mostly application with the internal surface. There are few reports available for the external complicated surface. Further, the finishing of blind holes, complicated internal surfaces is a yet unexplored area of study.

- The AFM processes depend on the abrasive-laden medium. The sedimentation and temperature rise are the major problem associated with the abrasive-laden medium [78]. The viscosity of the medium is changed during the process when the duration of the process is increased which decreases the effectiveness of the process. The search for economical, environmentally friendly and efficient medium is still in progress.

- There is a need to develop adjustable fixtures for complex workpieces, which can be adjusted according to the shape and size of the workpiece with minor changes in the experimental setup.

- According to a market survey, $50 \%$ of the AFM users demand process simulation to model, optimize the flow and predict the results by the use of numerical methods.

- MAAFM was very efficient for the finishing of nonmagnetic materials, but it is also necessary to explore the applications of MAAFM for magnetic materials. Also, there is not any report available for finishing of spherical surfaces by unconventional finishing processes.

- Finishing the MMCs or hard materials by standard abrasive laden medium was not appropriate because of low volumetric material removal rate, which may result in high processing time [95]. Therefore, it is necessary to increase the aggressiveness of abrasive laden medium by addition of suitable chemicals, which soften the metallic surface and assist the abrasive particles in mechanical abrasion. 


\section{Nomenclature}

$\begin{array}{ll}\text { Vol. } & \text { Volume } \\ C & \text { Abrasive to medium concentration } \\ \text { SL } & \text { Stroke length } \\ T & \text { Temperature } \\ R_{\mathrm{ai}} & \text { Initial roughness } \\ \Delta R_{a} & \text { Change in roughness } \\ P & \text { Pressure } \\ t & \text { Time } \\ B & \text { Magnetic flux density } \\ \text { OD } & \text { Outer diameter } \\ \text { ID } & \text { Inner diameter } \\ \text { RR } & \text { Reduction ratio }\end{array}$

\section{Abbreviations}

CFAAFM Centrifugal force assisted abrasive flow machining

CIP Carbonyl iron particle

DBG-AFF Drill bit-guided abrasive flow finishing

ECAFM Electrochemical assisted abrasive flow machining

ECM Electrochemical machining

HLX-AFM Helical abrasive flow machining

MR Magneto-rheological fluid

MRAFF Magneto-rheological abrasive flow finishing

MRAH Magneto-rheological abrasive honing

MMC Metal matrix composites

MRF Magneto-rheological finishing

MRR Material removal rate

R-AFF Rotary abrasive flow finishing

R-MRAFF Rotary magnetorheological abrasive flow finishing

SFAAFM Spiral flow assisted abrasive flow machining

UAAFM Ultrasonic assisted abrasive flow machining

Vol. \% \% composition volume by volume

wt.\% $\%$ composition weight by weight

\section{Greek letters}

$\varnothing \quad$ Helix angle

\# Mesh size

$\mu \quad$ Medium viscosity

$N$ Rotational speed

$F \quad$ Feed

I Current

$v \quad$ Frequency

$\Phi$ Diameter

$\lambda$ Amplitude

$B$ Magnetic flux density

$V$ Voltage

$T$ tesla

Authors acknowledge the financial support received from the Netaji Subhas University of Technology (Formerly Netaji Subhas Institute of Technology), New Delhi, for the research study entitled 'Study on influential parameters of hybrid AFM processes: A Review'.

\section{References}

1. H. Foellinger, Optimum parameters for dressing process of conventional grinding, Proc. Super Abras. 85 (1985) 8.228.37

2. A.J. Troglio, Performance evaluation of multi-stone honing tool by experimental design methods, Proc. Int. Honing Conf. M R03-232 (2003) 1-24

3. C.J. Evans, E. Paul, D. Dornfeld, Material removal mechanisms in lapping and polishing, CIRP Ann. 52 (2003) 611-633

4. I. Lazoglu, C. Manav, Y. Murtezaoglu, Tool path optimization for free form surface machining, CIRP Ann. 58 (2009) 101-104

5. V.K. Jain, P. Kumar, P.K. Behera, S.C. Jayswal, Effect of working gap and circumferential speed on the performance of magnetic abrasive finishing process, Wear 250 (2001) $384-390$

6. A. Lasemi, D. Xue, P. Gu, Recent development in CNC machining of freeform surfaces. A state-of-the-art review, Comput. Aided Des. 42 (2010) 641-654

7. A. Sidpara, V.K. Jain, Experimental investigations into surface roughness and yield stress in magnetorheological fluid based nano-finishing process, Int. J. Precis. Eng. Manuf. 13 (2012) 1-6

8. A. Sidpara, V.K. Jain, Effect of fluid composition on nanofinishing of single crystal silicon by magnetic field assisted finishing process, Int. J. Adv. Manuf. Technol. 55 (2010) $243-252$

9. A. Sidpara, V.K. Jain, Nano finishing of freeform surfaces of prosthetic knee joint implant, Proc. IMech E 226 (2012) $1833-1846$

10. C. Kumari, S.K. Chak, A review on magnetically assisted abrasive finishing and their critical process parameters, Manufactur. Rev. 5 (2018) 13

11. M. Tricard, W.I. Kordonski, A.B. Shorey, Magnetorheological jet finishing of conformal, freeform and steep concave optics, CIRP Ann. 55 (2006) 309-312

12. R.K. Jain, V.K. Jain, Specific energy and temperature determination in abrasive flow machining process, Int. J. Mach. Tools Manuf. 41 (2001) 1689-1704

13. S. Rajesha, Some studies to enhance the capabilities of abrasive flow machining process, $\mathrm{PhD}$ dissertation, IIT Roorkee, 2011

14. P. Balasubramanian, T. Senthilvelan, Optimization of machining parameters in EDM process using cast and sintered copper electrodes, Proc. Mater Sci. 6 (2014) $1292-1302$

15. L. Nagdeve, V.K. Jain, J. Ramkumar, Experimental Investigations into nano-finishing of freeform surfaces using negative replica of the knee joint, Proc. CIRP 42 (2016) 793-798

16. T.R. Loveless, R.E. Willams, K.P. Rajurkar, A study of the effects of abrasive flow finishing on various machined surfaces, J. Mater. Process Technol. 47 (1994) 133-151

17. J.C. Lambropoulos, T. Fang, P.D. Funkenbusch, S.D. Jacobs, M.J. Cumbo, D. Golini, Surface microroughness of optical glasses under deterministic microgrinding, Appl. Opt. 35 (1996) 4448-4462

18. H.S. Shan, A.K. Dubey, Micro machining by flow of abrasives, in Proc of 17th All India Manufacturing Technology design and Research Conference, Warangal, India, 1997, pp. 269-275, Allied publishers limited, Mumbai 
19. S. Kumar, V.K. Jain, A. Sidpara, Nanofinishing of freeform surfaces (knee joint implant) by rotational-magnetorheological abrasive flow finishing (R-MRAFF) process, Precis. Eng. 42 (2015) 165-178

20. R.E. Williams, K.P. Rajurkar, Metal removal and surface finish characteristics in abrasive flow machining, Mechanics of deburring and surface finishing processes. Am. Soc. Mech. Eng. 38 (1989) 93-106

21. R.E. Williams, K.P. Rajurkar, L.J. Rhoades, Performance characteristics of abrasive flow machining, Technical Paper of the Society of Manufacturing Engineers (SME) 1989, M R89-806

22. A. Sadiq, M.S. Shunmugam, Investigation into magnetorheological abrasive honing (MRAH), Int. J. Mach. Tools Manuf. 49 (2009) 554-560

23. B.H. Yan, H.J. Tzeng, F.Y. Huang et al., Finishing effects of spiral polishing method on micro lapping surface, Int. J. Mach. Tools Manuf. 47 (2007) 920-926

24. A.C. Wang, L. Tsai, K.Z. Liang et al., Uniform surface polished method of complex holes in abrasive flow machining, Trans. Nonferrous Met. Soc. China 19 (2009) 250-257

25. K.M. Reddy, A.K. Sharma, P. Kumar, Some aspects of centrifugal force assisted abrasive flow machining of $2014 \mathrm{Al}$ alloy, Proc. IMechE B 222 (2008) 773-783

26. L.J. Rhoades, T.A. Kohut, N.P. Nokovich, D.M. Yanda, Unidirectional abrasive flow machining, US patent 5,367,833, 1994

27. L.J. Rhoades, T.A. Kohut, Reversible Unidirectional abrasive flow machining. US 5070 652, 1991

28. L.J. Rhoades, Orbital and/or reciprocal machining with a viscous plastic medium. US, WO 90/0504 4, 1990

29. W.B. Perry, Abrasive flow machining-principles and practices. Proc. Non-tradit. Mach. Conf. (1989) s121-s127

30. B.S. Brar, R.S. Walia, V.P. Singh, M. Sharma, A robust helical abrasive flow machining (HLX-AFM) process, J. Inst. Eng. Ser. C 94 (2013) 21-29

31. T.A. El-Taweel, Modelling and analysis of hybrid electrochemical turning magnetic abrasive finishing of $6061 \mathrm{Al} /$ $\mathrm{Al}_{2} \mathrm{O}_{3}$ composite, Int. J. Adv. Manuf. Technol. 37 (2008) 705-714

32. A. Mishra, P.M. Pandey, U.S. Dixit, Modeling of material removal in ultrasonic assisted magnetic abrasive finishing process, Int. J. Mech. Sci. 131-132 (2017) 853-867

33. J.K. Sambharia, H.S. Mali, Characterization and performance evaluation of developed alternative polymer abrasive gels for abrasive flow finishing process, Int. J. Precis. Technol. 5 (2015) 185-200

34. J.R. Gilmore, L.J. Rhoades, Abrasive polishing method, apparatus and composition, US Patent 6,273,787, 2001

35. S. Singh, H.S. Shan, P. Kumar, Morphology and integrity of surfaces finished by centrifugal force assisted abrasive flow machining, Int. J. Adv. Manuf. Technol. 39 (2008) 11711179

36. J. Kozak, K.E. Oczos, Selected problems of abrasive hybrid machining, J. Mater. Process Technol. 109 (2001) 360-366

37. M.S. Cheema, G. Venkatesh, A. Dvivedi et al., Developments in abrasive flow machining: a review on experimental investigations using abrasive flow machining variants and media, Proc. IMechE B 226 (2012) 1951-1962

38. A.R. Jones, J.B. Hull, Ultrasonic flow polishing, Ultrasonics 36 (1998) 97-101
39. R.S. Mulik, P.M. Pandey, Experimental Investigations and optimization of ultrasonic assisted magnetic abrasive finishing process, Proc. IMechE B 225 (2011) 1347-1362

40. L. Nagdeve, V.K. Jain, J. Ramkumar, Nanofinishing of freeform/sculptured surfaces: state-of-the-art, Manufactur. Rev. 5 (2018) 6

41. S. Singh, H.S. Shan, Development of magneto abrasive flow machining process, Int. J. Mach. Tools Manuf. 42 (2002) 953-959

42. H.J. Tzeng, B.H. Yan, R.T. Hsu et al., Self-modulating abrasive medium and its application to abrasive flow machining for finishing micro channel surfaces, Int. J. Adv. Manuf. Technol. 32 (2007) 1163-1169

43. W.B. Kim, S.J. Lee, Y.L. Kim et al., The electromechanical principle of electrorheological fluid-assisted polishing, Int. J. Mach. Tools Manuf. 43 (2003) 81-88

44. K.I. Jang, J. Seok, B.K. Min et al., An electro-chemomechanical polishing process using magnetorheological fluid, Int. J. Mach. Tools Manuf. 50 (2010) 869-881

45. A. Sidpara, V.K. Jain, Experimental investigations into forces during magnetorheological fluid based finishing process, Int. J. Mach. Tools Manuf. 51 (2011) 358-362

46. K.I. Jang, D.Y. Kim, S. Maeng et al., Deburring micro-parts using a magnetorheological fluid, Int. J. Mach. Tools Manuf. 53 (2012) 170-175

47. S. Jha, V.K. Jain, Design and development of the magnetorheological abrasive flow finishing (MRAFF) process, Int. J. Mach. Tools Manuf. 44 (2004) 1019-1029

48. S. Jha, V.K. Jain, R. Komanduri, Effect of extrusion pressure and number of finishing cycles on surface roughness in magnetorheological abrasive flow finishing (MRAFF) process, Int. J. Adv. Manuf. Technol. 33 (2007) $725-729$

49. V. Gudipadu, P. Kumar, A.K. Sharma, On ultrasonic assisted abrasive flow finishing of bevel gears, Int. J. Hull. 36 (2015) 97-101

50. M. Das, V.K. Jain, P.S. Ghoshdastidar, Analysis of magnetorheological abrasive flow finishing (MRAFF) process, Int. J. Adv. Manuf. Technol. 38 (2008) 613-621

51. M.R. Sankar, J. Ramkumar, V.K. Jain, Experimental investigation and mechanism of material removal in nano finishing of MMCs using abrasive flow finishing (AFF) process, Wear 266 (2009) 688-698

52. M.R. Sankar, J. Ramkumar, V.K. Jain, Rotational abrasive flow finishing (R-AFF) process and its effects on finished surface topography, Int. J. Mach. Tools Manuf. 50 (2010) $637-650$

53. L.J. Rhoades, Abrasive flow machining: a case study, J. Mater. Process. Technol. 28 (1991) 107-116

54. K. Przyklenk, Abrasive flow machining: a process for surface finishing and deburring of workpiece with a complicated shape by means of an abrasive laden medium, Adv. Nontradit. Mach. PED ASME 22 (1986) 101-110

55. R.S. Walia, H.S. Shan, P. Kumar, Determining dynamically active abrasive particles in the media used in centrifugal force assisted abrasive flow machining process, Int. J. Adv. Manuf. Technol. 38 (2008) 1157-1164

56. A. Ghosh, A.K. Malik, Manufacturing Science, 3rd edn. EWP, New Delhi (2003), pp. 329-421

57. P. Ranjan, R. Balasubramaniam, V.K. Suri, Development of chemo-mechanical magnetorheological finishing process for super finishing of copper alloy, Int. J. Manuf. Technol. Manag. 27 (2013) 130-141 
58. V.K. Jain, A. Sidpara, R. Balasubramaniam et al., Micromanufacturing: a review. Part 1. Proc. IMechE B 228 (2014) 973-994

59. B.S. Brar, R.S. Walia, V.P. Singh et al., Effects of helical rod profiles in Helical Abrasive Flow Machining (HLX-AFM) process, International Mechanical Engineering Congress and Exposition, Houston, 2015

60. V.K. Jain, S.G. Adsul, Experimental investigations into abrasive flow machining, Int. J. Mach. Tool Manuf. 40 (2002) 1003-1021

61. L. Fang, J. Zhao, K. Sun, D. Zheng, D. Ma, Temperature as sensitive monitor for efficiency of work in abrasive flow machining, Wear 266 (2009) 678-687

62. P.J. Davies, A.J. Fletcher, The assessment of rheological properties of various polyborosiloxane/grit mixtures as utilized in AFM, Proc. IMechE C 209 (1995) 409-418

63. G. Venkatesh, Performance study of a new polymer media for AFM. M. Tech. Dissertation, IIT Roorkee, 2010

64. V.K. Jain, S.G. Adsul, Experimental investigations into abrasive flow machining, Int. J. Mach. Tools Manuf. 40 (2000) 1003-1021

65. V.K. Gorana, V.K. Jain, G.K. Lal, Experimental investigation into cutting forces and active grain density during abrasive flow machining, Int. J. Mach. Tools Manuf. 44 (2004) 201-211

66. A.C. Wang, S.H. Weng, Developing the polymer abrasive gels in AFM process, J. Mater. Process Technol. 192-193 (2007) 486-490

67. M.R. Sankar, S. Mondal, J. Ramkumar et al., Experimental investigations and modelling of drill bit guided abrasive flow finishing (DBG-AFF) process, Int. J. Adv. Manuf. Technol. 42 (2009) 678-688

68. R.S. Walia, H.S. Shan, P. Kumar, Abrasive flow machining with additional centrifugal force applied to the media, Mach. Sci. Technol. 10 (2008) 341-354

69. M.R. Sankar, J. Ramkumar, V.K. Jain, Experimental investigations into rotating workpiece abrasive flow finishing, Wear 267 (2009) 43-51

70. L. Dabrowski, M. Marciniak, T. Szewczyk, Analysis of abrasive flow machining with an electrochemical process aid, Proc. IMechE B 220 (2006) 397-403

71. B.S. Brar, R.S. Walia, V.P. Singh, Regression model for Electro-Chemical Aided Abrasive Flow Machining $\left(\mathrm{ECA}^{2} \mathrm{FM}\right)$ process, in 5th International \& 26th All India Manufacturing Technology, Design and Research Conference (AIMTDR 2014) December 12th-14th, 2014, IIT Guwahati, Assam, India

72. G. Venkatesh, A.K. Sharma, P. Kumar, On ultrasonic assisted abrasive flow finishing of bevel gears, Int. J. Mach. Tools Manuf. 89 (2015) 29-38

73. S. Singh, H.S. Shan, P. Kumar, Wear behavior of materials in magnetically assisted abrasive flow machining, J. Mater. Process. Technol. 128 (2002) 155-161

74. S. Kumar, S.S. Hiremath, Machining of internal features using the developed abrasive flow machine, in Conference on Advances in Production and Industrial Engineering, NIT Trichy, India, 20-21 February 2015, 12, 298-303

75. R.E. Williams, K.P. Rajurkar, Stochastic modeling and analysis of abrasive flow machining, Trans. ASME, J. Eng. Ind. 114 (1992) 74-81

76. H.J. Tzeng, B.H. Yan, R.T. Hsu et al., Finishing effect of abrasive flow machining on micro slit fabricated by wireEDM, Int. J. Adv. Manuf. Technol. 34 (2007) 649-656
77. E. Uhlmann, V. Mihotovic, A. Coenen, Modelling the abrasive flow machining process on advanced ceramic materials, J. Mater. Process. Technol. 209 (2009) 6062-6066

78. D. Jung, W.L. Wang, A. Knafl et al., Experimental investigation of abrasive flow machining effects on injector nozzle geometries, engine performance, and emissions in a DI diesel engine, Int. J. Automot. Technol. 9 (2008) 9-15

79. Y.C. Lin, H.M. Chow, B.H. Yan et al., Effects of finishing in abrasive fluid machining on microholes fabricated by EDM, Int. J. Adv. Manuf. Technol. 33 (2007) 489-497

80. K. Saraswathamma, S. Jha, P.V. Rao, Experimental investigation into ball end magnetorheological finishing of silicon, Precis. Eng. 42 (2015) 218-223

81. S. Sarah, Y. Lam, A.E. Smith, Cascade-correlation neural network modeling of the abrasive flow machining process, Int. J. Ind. Eng. Theory Appl. Pract. 3 (1998) 898-905

82. E. Uhlmann, S. Richarz, V. Mihotovic, Substrate pretreatment of cemented carbides using abrasive flow machining and laser beam ablation, Prod. Eng. 3 (2009) 81-86

83. R.E. Williams, D.F. Walczyk, H.T. Dang, Using abrasive flow machining to seal and finish conformal channels in laminated tooling, Rapid Prototyping J. 13 (2007) 64-75

84. S. Singh, H.S. Shan, P. Kumar, Morphology and integrity of surfaces finished by centrifugal force assisted abrasive flow machining, Int. J. Adv. Manuf. Technol. 39 (2008) 11711179

85. J. Kenda, F. Pusavec, G. Kermouche et al., Surface integrity in abrasive flow machining of hardened tool steel AISI D2, Proc. Eng. 19 (2011) 172-177

86. R.E. Williams, Investigation of the abrasive flow machining process and development of a monitoring strategy using acoustic emission, $\mathrm{PhD}$ Thesis, The University of Nebraska - Lincoln, USA, 1993

87. A.K. Sharma, S. Rajesha, G. Venkatesh et al., A natural polymer abrasive media for the abrasive flow machining and a process for preparation, Patent number 1349/DEL/2011, India, 9 May 2011

88. H.S. Mali, A. Manna, Current status and application of abrasive flow finishing processes: a review, Proc. IMechE B 223 (2009) 809-820

89. K.K. Kar, N.L. Ravikumar, P.B. Tailor et al., Performance evaluation and rheological characterization of newly developed butyl rubber based media for abrasive flow machining process, J. Mater. Process. Technol. 209 (2009) 2212-2221

90. M.R. Sankar, V.K. Jain, J. Ramkumar, Y.M. Joshi, Rheological characterization of styrene-butadiene based medium and its finishing performance using rotational abrasive flow finishing process, Int. J. Mach. Tools Manuf. 51 (2011) 947-957

91. M. Sarkar, V.K. Jain, Nanofinishing of freeform surfaces using abrasive flow finishing process, Proc. IMechE B 231 (2015) 1501-1515

92. A.D. Ghadikolaei, M. Vahdati, Experimental study on the effect of finishing parameters on surface roughness in magneto-rheological abrasive flow finishing process, Proc. IMech E, Part B 229 (2014) 1517-1524

93. K. Saito, Finishing and polishing of free-form surfaces, Bull. Jpn. Soc. Mech. Engg. 18 (1984) 104-109

94. M.R. Sankar, V.K. Jain, J. Ramkumar, Abrasive flow machining (AFM): An Overview. https://www.research gate.net/publication/228747468_Abrasive_flow_machi ning_AFM_An_Overview (20̄11, accessed $15 \overline{ }$ January 2018) 
95. J. Sambharia, H.S. Mali, Recent developments in abrasive flow finishing process: A review of current research and future prospects, Proc. IMechE B 233 (2017) 1-12

96. H.S. Mali, A. Manna, Optimum selection of abrasive flow machining conditions during fine finishing of $\mathrm{Al} / 15 \mathrm{wt} \% \mathrm{SiC}-$ MMC using Taguchi method, Int. J. Adv. Manuf. Technol. 50 (2010) 1013-1024

97. V.K. Jain, Magnetic field assisted abrasive based micro/ nano-finishing, J. Mater. Proc. Technol. 209 (2009) 6022-6038
98. V.K. Jain et al., Nano-finishing techniques: a review, Proc. Inst. Mech. Eng. C 226 (2012) 327-346

99. P.K. Basera, V.K. Jain, Nano-finishing of aircraft blade bearing by magnetic abrasive finishing (MAF) process, 2nd Annual International Conference on Material Science, Metals and Manufacturing (M3 2012), 2012, pp. 129-136

100. T.S. Bedi, A.K. Singh, Magnetorheological methods for nanofinishing a review, Part. Sci. Technol. 34 (2016) $412-422$

Cite this article as: Chinu Kumari, Sanjay Kumar Chak, Study on influential parameters of hybrid AFM processes: a review, Manufacturing Rev. 6, 23 (2019) 